\title{
Do the arguments of Sāinkhya and Mīmāmsā on the law of karma imply or refute the ecxistence of God?
}

\author{
Vignesh Karthik K.R.
}

\section{INTRODUCTION}

The genesis of the Indian Culture dates back to several millennia ago; and ever since, its legacy has led us through the Vedic concept of Dharma - enriching every aspect of it like language, religion, customs, beliefs, traditions, cuisines, art, music, values and many a times even emotions. This culture has inspired many writers to dwell into the logic and reasoning behind every motive - especially, how good and ethical they will stand in the modern world. One such Law that has constantly been under the limelight, with writers often opposing each other's opinion regarding the connotation and context included in its covenant, is the 'Law of Karma', which revolves around fate, its causes and effects.

This essay uses the theory of Karma along with its various hypotheses and tries to perceive whether God exists or not. The thought of God first occurred to people when they saw the various creations around them which have been existing from time immemorial. As humans, we think of God as a super human (say 8 hands) A few think God is white and a few, black. There are a few who feel he is brown too. We as Indians have various manifestations of God - Monkey, Cow, Eagle, Snake, Black, White, Man, Woman etc.

In purview of God's existence, this essay will be dealing withfour schools of thought. 1. Implying His Godliness and existence - with Sages from Nyaya and Vaisesika propounding this. 2. Refuting His eternal being and existence - with Sages from Samkhya and Mimamsa preaching this.

The meaning of Karma that our fate is caused by our actions, has been conveniently forgotten by mankind. At such a juncture, the propaganda of these four schools has immense meaning in concluding whether God is extant or not. Also these arguments throw some light into who exactly created our paradise.Below is a logically plotted recollection of the statements and thoughts put forth by the four schools.

\section{A SAMKHYAN'S TAKE}

The elementary judgments that the Samkhyans make are based on the clear understanding of the concepts of the Gross and Rudimentary Elements. The five aspects of your senses (namely, sound, touch, visual colour, taste and odour) are the Rudimentary Elements and the five constituents of our biosphere (namely, Space, Air, Fire, Earth and Water - collectively known as the Pancha Boothas) are referred to as the Gross Elements. ${ }^{1}$ The trigunas -Tamas, Rajas and Sattva - are the forces that help in survival on this planet. Tamas is inertia (static nature), Rajas is activity (energy) and Sattva is transcendence (vibrance). Everything in the world is said to have these three aspects. Absence of these three elements will disable you from holding anything together. ${ }^{2}$ The Samkhyans believe that the subtle body is the soul. It has no reference with Purusha or Spirit. The spirit is the observer and the subtle body associates with everything else other than this spirit. The archaic laws and beliefs state that the subtle bodies were formed when emanations from the nature began, one subtle body for each spirit. This body is so unconfined and untrammelled that it can even enter a solid piece of stone. It goes on deserting and occupying one six-sheathed body after another as it is basically devoid of any experience. Without corresponding to a physical body with six sheaths it can't gather experience. So it migrates from body to body gaining from each, to attain Moksha once it has acquired ideally. ${ }^{3}$

The dispositions are virtue and vice, wisdom and ignorance, passion and dispassion, power and weakness. The Will endowed is directly connected to them. The subtle body that is connected to the will becomes invested with these dispositions. These can be both innate and man-made. Ascent to higher planes is obtained by virtue and the descent is because of vice. From wisdom results highest good, else bondage is what Karma has written for you! ${ }^{4}$

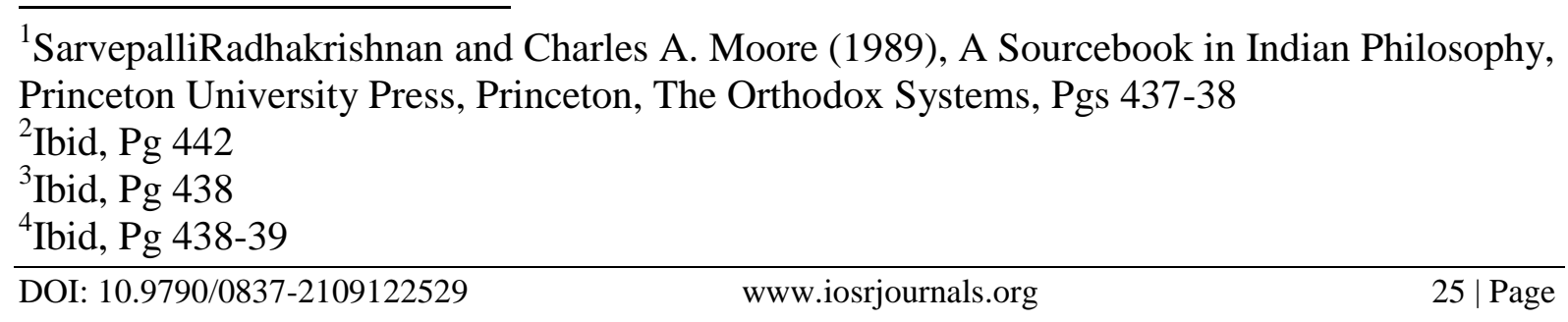


These moral or immoral temperaments that the body has learnt on the way are all due to the actions that its physical body has performed. As a result, we can clearly prove here that Karma is because of our actions and Nature is what created all what exists now.From dispassion results, 'mergence into the nature'! Those who are free from passion but ignorant of the true nature of the spirit get entangled in the cycle again. When a person worships these as the spirit, they succumb to the cycle of karma and will be born again and again until they differentiate. ${ }^{5}$ Just the way a shadow cannot exist without the object, a cognitive apparatus (Linga) cannot sustain without the subtle body. Linga includes the rudimentary elements and is a means to knowledge. ${ }^{6}$

According to this belief, actions that lead to contentment are either external or internal. The external forms of contentment are sense organs. One has to transcend these to be satisfied. Internal forms of Content refers to one's intellectual capacity. One deliberately accomplishes these acts, thus spelling out his/her Karma. The contentment from this source arises out of four concepts namely Necessity for objective evolution, Existence of sense organs and internal organs, Existence of the notion of Discriminative Wisdom and lastly the notion of transcending the Fear of Death. ${ }^{7}$

"Granted that the evolution is due to nature alone, a question may arise that there will be no emancipation of the spirit because nature is eternally active and her operations never cease. " 8 For example, When a cook finishes the cooking in which he was engaged, he will obviously have to retire from work for some time before he begins work at the kitchen again. Similarly nature being urged to act brings about this emancipation and then stops her operations with regard to that spirit. This action for another's sake is just like the action for one's own benefit. ${ }^{9}$

Assuming that the above said assumptions and dispositions are all true, a doubt arises because it is only a sentient being that acts either for its own or for another's purpose and the nature being insentient, cannot act in the manner described and as such she requires a sentient controller. The spirits residing in the bodies cannot be such controllers, because conditioned spirits are ignorant of the true character of nature. Therefore there must be some omniscient sentient being controlling the operations of nature while many people have given the name "GOD". 10

Literature does not have evidence that suggests this. It is in fact been observed that many insentient objects can also act towards definite ends. For example, milk, which is insentient, flows for the nourishment of the calf. Similarly, nature, though insentient, could act towards the emancipation of the spirit. It would not be right to urge that the flow of milk is due to the superintending care of God. ${ }^{11}$

We can also argue against his existence because God being the lord of universe has all that he requires. In such a scenario, creation of the world, can neither have any selfish motives nor can it be solely due to benevolence. Pity consists of desire to remove others' pain. However, before creation, the spirits are devoid of pleasure or pain,thereby removal of what could be God's compassion? If pain subsequent to the creation is the cause of creation, then we'd be in an inextricable noose of interdependence for creation is due to pity and pity is due to creation! $!^{12}$ Sages of Mimansa also argue on similar grounds in this regard. ${ }^{13}$

The only motive of nature is fulfillment of another's purpose and thus proves the Samkhyans to be correct. To get rid of desire one has to satisfy that longing. Similarly, nature works in a manifest manner towards releasing the spirits. $^{14}$

Actually, no spirit is bound, nor does it migrate, nor is any spirit emancipated. Nature having many vehicles is bound, migrates and is released. Bondage, migration and release are linked to spirit in the manner as defeat and victory are attributed to a king. Similarly experiences and emancipation though really belonging to nature are attributed to the spirit on account of non-discrimination of spirit from nature. ${ }^{15}$

Nature binds herself in seven forms - Virtue, Vice, Error, Dispassion, Passion, Power and Weakness. Through one of these forms she causes deliverance or the final release - the wisdom that one needs for emancipation!

\begin{tabular}{l}
\hline${ }^{5}$ Ibid, Pg 440 \\
${ }^{6}$ Ibid, Pg 439 \\
${ }^{7}$ Ibid, Pg $440-41$ \\
${ }^{8} \mathrm{Ibid}, \operatorname{Pg} 442$ \\
${ }^{9} \mathrm{Ibid}, \operatorname{Pg} 442$ \\
${ }^{10} \mathrm{Ibid}, \operatorname{Pg} 442-43$ \\
${ }^{11} \mathrm{Ibid}, \operatorname{Pg} 443$ \\
${ }^{12} \mathrm{Ibid}, \operatorname{Pg} 443$ \\
${ }^{13} \mathrm{Ibid}, \operatorname{Pg} 499-501$ \\
${ }^{14} \mathrm{Ibid}, \operatorname{Pg} 443$ \\
\hline${ }^{15} \mathrm{Ibid}, \operatorname{Pg} 444$ \\
\hline DOI: $10.9790 / 0837-2109122529$
\end{tabular} 
Once this is done she will never bring about any experience to that particular spirit. ${ }^{16}$ Thus, using nature's guidelines man performs certain acts that give his spirit the experience and the same acts were the ones that wrote his final destination, making his own Karma.

Virtue and the other such dispositions cease to function as causes for more experience, because of the attainment of perfect wisdom in the case of a given spirit. But, the spirit has to remain invested with the body due to past impressions - only a natural bodily fall can remove a spirit and thus, it falls by itself. Once the separation is over, nature ceases to act and he attains eternal and absolute isolation! ${ }^{17}$

\section{MIMAMSA'S SLOKAVARTHIKA PREACHES}

To all the people ignorant of the association between a particular word and its meaning, Mimamsa says that the relation comes from a well established form through previous traditions (the people who knew it before ad infinitum) and thus there can be no beginning of the relation thereby it must be held to perpetuity. The relationship between the word and its meaning does not change at all - this is an eternal link. ${ }^{18}$

The innocent may question, 'at the time when the earth did not exist, what could have been the condition of the universe? And, what would have been the position of the Creator himself? Mimamsa states that at this time when no one really existed, who would know him and who would explain his character to the later created people? If you say that he is not perceivable by a man, then without perception or cognition how can we determine the fact of his existence? ${ }^{19}$

However, his desire to destroy the world (that is, Pralaya) is hardly accountable or understandable. Even if he is known in form, the fact that he is the creator will not be known because at the infancy stage of living beings the capacity to understand ones origin is at a very minimal level. Similarly the Veda that would proceed from him can only be doubted and hence that cannot be admitted as a proof of his existence or the power of creation. $^{20}$

If all the actions of the persons are to be destroyed at the time of dissolution, then no further creation would be possible because when all the actions are destroyed there will be no means to bring out actions. Such a stance clearly shows that the deeds of man do not lead to his final fate and this is against the Karma theory, proving the opposition (in this case Vaisesika) wrong. ${ }^{21}$

The use of the Mahabharata and other such epics in reference to dharma and other virtues is to praise and exemplify certain duties and sacrifices in the form of telling stories. Similarly Vedic passages that seem to mention certain practices are only for praising certain sacrifices. Hence the idea of Prajapathi creating the world obtained from the Puranas would also be a mistaken one. We must admit that all the stories making up the Puranas could have some object of praise or dispraise and that some is prescribed either in the Vedas or in the Puranas. 22

From a person who is extremely pure the world (product) can't be impure as it is found to be. Existence of dharma and pain in this world too is not reasonable. In addition when activities are dependent on dharma and other such assets then it means, accepting something else or some other agency other than God's desire. If you say that ignorance is natural and is not stimulated by anyone, then it can't be eliminated completely and will always be with you inevitably and therefore you can't have deliverance at all. ${ }^{23}$

\section{SAGES OF NYAYA AND VAISESHIKA'S ARGUMENTS}

Sages of Nyaya proposed that God was existent and he answered the question of one reaching heaven with sacrifices even without God's help. Nyaya replies thus, "Knowledge needs an external source as there is creation and destruction. No one other than GOD can be relied upon. A testimony's quality is based on the speaker. No one else can come up with such quality content other than GOD. Only he can be the subject of the Vedas and only his help will make your actions lead you to heaven." 24

If God cannot be perceived, and if there is no inference with relation to Him, then obviously God is nonexistent. Nyaya banishes this thought with his ideology that the Absence of the perception of the existence of

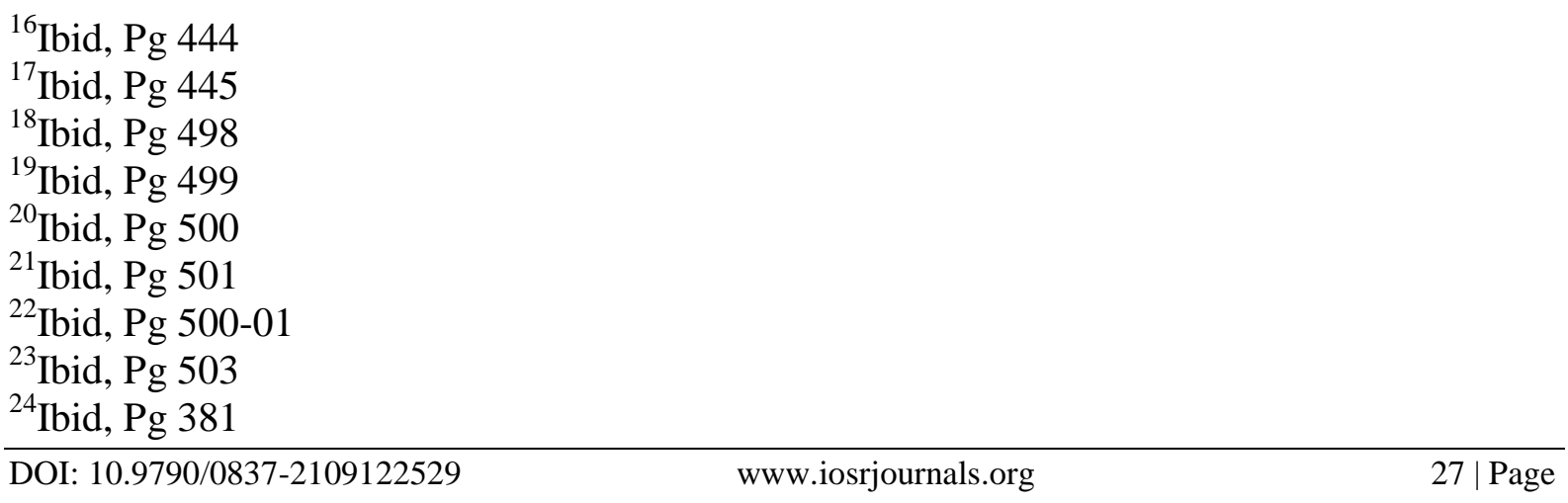


God doesn't prove his non-existence. According to the literature, there are proofs to establish the evidence of God. When you try to infer his non-existence from the absence of body and motive for action, you are denying the truth. Trying to deny the truth in justifying His non-existence itself establishes existence. ${ }^{25}$ When questioning the will that leads to one doing an action, you will realize that any activity can occur only if desired. A command is needed with the desired end of the doer. For example, if an atom was filled with will, it can be called intelligent because an unintelligent thing can produce an effect only when driven by an intelligent being. This proves that there is an existence of command and goes on to establish the existence of God. ${ }^{26}$

Vaisesika shows proof of God in the form of scriptural authority and inferential reasoning. The inferential reasoning revolves around the four substances of air, earth, water and fire brought in by someone who has the knowledge pertaining to them because they are effects. Anything that is an effect has an architect and is preceded by one having cognition of it. The well known example of a jar and its potter can be referred to. Hence, the elementary substances, that are effects, must be preceded by someone having familiarity to them.There are suitable arguments that state that these four substances are not necessarily effects (especially in the case of earth). But, Vaisesika certifies that the conclusion pertaining to the elementary substances as an effect is substantial enough. He says that the Earth is made up of parts and anything that is made up of parts is an effect. ${ }^{27}$ Sages of Vaisesika go on to say that perception is not valid all the time. In a few cases, going by perceptions the path would lead us to nowhere. There are often things that can be inferred but not perceived. Such facts should be adhered to. Example, the Movement of stars - Perception says that stars move. But only fact or inference says that they are at different positions. ${ }^{28}$

Does the nature of the doer necessarily consist of being bodied? Or is it about the capability in bringing about the effects? - are some questions that are put in response to the opposition. The force that drives the physic to action matters. The physic might differ based on the karma. The driver is only responsible solely. The body's work ends with bringing in action and desire because it can't be the object and doer at the same time. Inanimate things are out to work by an intelligent being only through his desire and effort, thereby proving the existence of God. ${ }^{29}$ Dharma is a concept that they vouched for. Considered to be the property of man, it is an agent that is a means of happiness and final deliverance. Laid down by the Vedas, it is produced by the contact of man's internal organs delivered through pure thoughts and determination. It is subjective. However, common ways of attaining dharma are being free from lust, purity of intentions, absence of anger and fasting. It is an effect and must come to an end. It is Destructible on experiencing and leads to deliverance. It is sometimes immediate; sometimes it takes ages. But no matter the time it can't be destroyed in parts. It's a single entity. It is destroyed once true knowledge is achieved. Where there is true knowledge, there is no need for dharma. ${ }^{30}$

Thus to acquire true knowledge about the self it is necessary to meditate and when this trance reaches the ideal stage, the self disorients itself with the body and the mind and the true nature of the self is cognizable. ${ }^{31}$

Vaisesika popularized the Theory of Karma with reference to Dharma, Adharma and Actions made by Man. When a man with due intelligence (knowledge) carries out acts of dharma without any thought of result, he will be born into a pure family and having thus born he will have a longing to find out the means for absolute removal of pain. With this end in mind he takes himself to a qualified teacher and obtains true knowledge of the six categories from him (Samkhya, Mimamsa, Nyaya, Vaisesika, Yoga and Vedanta). This removes his ignorance. After thorough dispassion when he is free from pleasures, Dharma and Adharma stop. His previous lives and his experiences with pain and pleasure are all in the nature of pure dharma - tending towards peace, cessation and liberation. This produces happiness of contentment in him and disregard for the body. The happiness of the highest truth will result in this dharma's disappearance too. We might also say mind influences the self by the dharma born out of yogic practices, but dharma being an product of such a practice is also destructible thereby nothing is left to help the mind. During deliverance, one will transcend the Cause-Effect phenomena, the Dharma-Adharma cycle and also surpass their Body-Mind links. ${ }^{32}$

\section{UNDERSTANDING KARMA}

A self's growth when acting according to the residue created will help the situation. The Cause - Effect syndrome is present in all acts of life. Never worry much about the effect. Think of the cause and you will

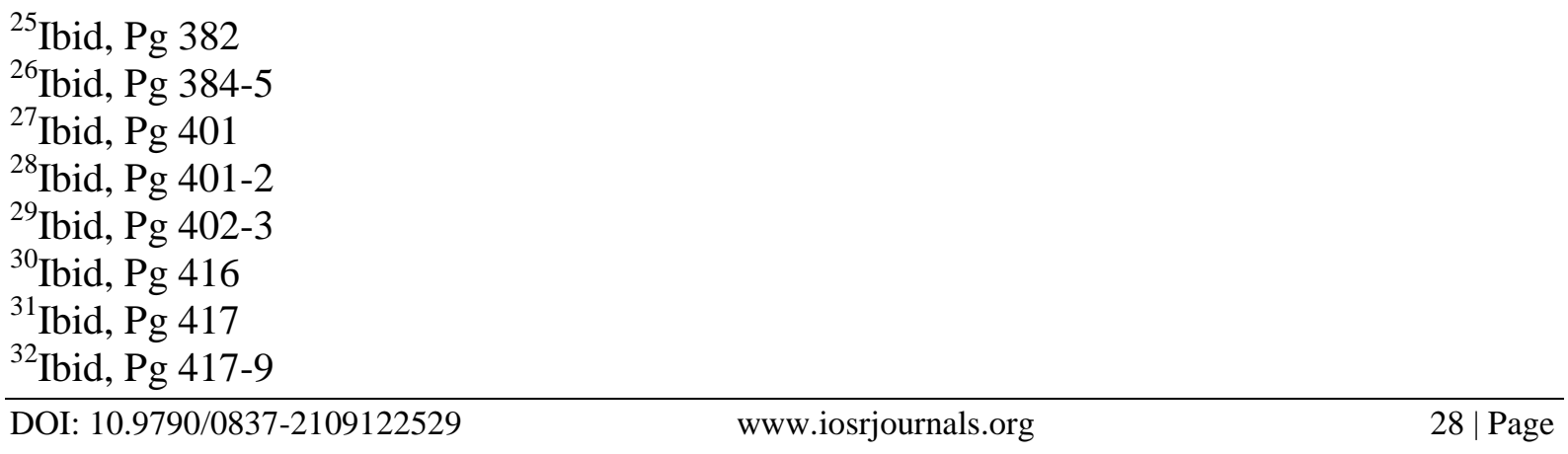


eventually perform the right act. Obviously, the result of such an act will be desirable. Karma as a concept helps us to think more about the cause and be aware of both the self and the surrounding. It is something that is done by oneself and its not what life does to you. In simpler terms, it is your choice. It is your actions that bring you bliss or sadness. Karma is your action and no other being's action will affect your liberation or bondage.

Moreover, if it was God's deed, then how can you break it? Only because it is by you, it can be undone. This act of undoing it will give you experiences that will help you finally attain Moksha. The reality is that you are always doing something whether awake or asleep - at various dimensions! And the formula is simple - If you're aware, you'll cause karma of liberation. If you're unaware, you'll cause karma of bondage! Karma can be caused when alone too. It is not interaction with somebody but, something that's happening within you. Bondage, Problems and such Dispositions can make you stronger and will serve as a means to liberation with awareness.

We are like the caterpillars. We weave a cocoon around ourselves, building it with our actions. This cocoon is really important for us and is just as necessary for a caterpillar. Ironically, it can take his life if he doesn't break it one day. Similarly, if we stay within those walls that we created because of our actions, liberation will not be the end product. Only when he breaks it, he becomes a butterfly, being free to fly! If he doesn't he dies inside the cocoon. Similar is the case with karma. If you snap the wall, it will be the source of liberation. Something extra-ordinary will happen. A worm can't imagine how blissful it is to be a butterfly. The same is the case with the self. That much bliss it is to be liberated, and the spirit is oblivious of its intensity.

If you die in it, it is the greatest bondage because you're dying of your own actions. The bondage is your creation and hence the liberation should be your doing as well. The environment can aid you but it is an inside job - a self awakening that will actually help you. If you look at life as a stepping stone for a larger responsibility, then you will face no failures. On the other hand, if you wish to see the simple events and occurrences as goals of life then you might be forced to witness failure and success in the form of bondage.

For eons, it has been inculcated in the Indians that one's life is only about Mukhti. This is not a new concept at all. Marriage, business or social life and the way one lives are all means to get to this liberated echelon. Whether you are a Sanyasi or in Sansaara, your only goal is Moksha. The goal is the same for everyone. If you have the capacity to walk alone (Sanyasi), reach liberation that way. If you want some 'fun', walk with the entertaining nuances that you desire for (Sansaara). If you want to get to this sought after position quickly, walk alone. You want to go there but in no hurry, you have the time, you can very well go with a group. You have a choice, but the goal is the same.Success is never just out of desire. You need the capacity and the capability to render to its needs and you should be able to earn it.

Success and failure are just ideas. The demarcation of their meanings changes in context and in person. What success or failure is, is your idea and need not necessarily be followed by a fellow being. Instead of changing the world, you change your idea and be aware of the situations around you.

Also, don't become a slave to an idea that someone else had seeded. Don't deceive yourself. Every idea, thought or emotion you have is picked up from somewhere and this rules you from within. The basis for it could be from your religion, society, culture or the values that you have been taught to believe in. Success enriches the soul only when you are not being a slave to a stranger's idea. Every action can take your life if you get lost in it. When you're in ignorance, in the same train you will meet suffering. This suffering is a means that will push you towards liberation. You will slowly start seeking. When you don't seek and if you begin to feel that ignorance is bliss you will lose out. The choice is yours - whether to be blissful and live life with a sense of awareness or just to deceive yourself and follow a stranger's route to the so-called rank of being a liberated soul.

\section{VI.}

\section{CONCLUSION}

The idea of God is an exaggerated version of ourself. No matter the dictum you've got on any language, you can't define yourself completely. When this supposedly simple task itself is not possible, how can you define the sourceofcreation?One thing is common among all four schools is that, they have advocated dissolution of the self into the source of creation and the idea that, this liberation can't be known but can only be experienced as it happens. They differ not because they disapprove the idea of dissolution but because their methods to this salvation are different. A few have room for 'GOD' and the others don't. If you believe in God being there or even if you strongly feel that God is not a force that is present in this mortal land, it doesn't matter as belief has nothing to do with reality. Commonality factor, in spite of the differences is the fact that, they have devised methods for the believers and the non-believers to become what we should be or to eventually attain liberation. Whether you believe in the existence of God or not, you'd want to know it and experience it at one point in your life. This longing will lead to seeking which results in the possibility of knowing and that's the possibility of liberation.

\section{BIBILIOGRAPHY}

[1] SarvepalliRadhakrishnan and Charles A. Moore (1989), A Sourcebook in Indian Philosophy, Princeton University Press, Princeton. 